\title{
ON THE INITIAL LOCUS \\ OF SYNTACTIC CHANGE: VERBAL GERUND AND ITS HISTORICAL DEVELOPMENT*
}

\author{
Osamu Koma \\ Tokyo Gakugei University
}

\begin{abstract}
Various attempts have been made to describe the historical development of English gerundive constructions. It seems to me, however, that they have left at least two problems unexplored: first, the external structure of gerunds, and second, the semantics of those present participles which traditional grammarians regarded as a main factor leading to the development of the gerundive construction. On the basis of my investigation of Paston Letters of the fifteenth century, I will claim that the early stage of this development was sensitive to the external environments of the construction. Moreover, I will, from the semantic point of view, substantiate the traditional account that gerunds acquired some verbal properties from present participles.
\end{abstract}

1. Introduction. One of the interesting aspects of syntactic development of English gerundive constructions is their acquisition of verbal characteristics in ME.

In this paper I will consider this aspect of change in a different framework from that which previous studies have presupposed.

Recent studies in this field are mainly concerned with the factual observation relating to the development of internal structure of gerunds. Thus, Tajima 1985 presents detailed usages of gerunds in ME on the basis of a large corpus of this period. Other philological studies, most of which use a statistical approach to deal with particular literary works or authors, also provide us with much information about the chronology of gerunds.

Based on these accumulated factual data, some linguists have attempted to characterize the underlying grammar changes in the frame-

* The present paper is a revised version of a paper read at the 4th General Meeting of the ELSJ held at Tsuda College in November 1986. I am very grateful to the participants for their invaluable comments. This work was supported partly by a Grant-inAid for Scientific Research from the Japanese Ministry of Education, Grant No. 62710263 . 
work of generative grammar. For example, Koma 1980 argues that the acquisition of verbal properties can be described as the innovation of phrase structure rules within the permissible bounds of the X-bar theory. ${ }^{1}$

Having surveyed these previous studies, whether philological or theoretical, we find that they have at least two serious defects.

First, most grammarians have focused their attention on the internal structure of gerunds. This biased attitude has led them to believe that the development of verbal gerunds was Autonomous; that is, it occurred independently of their external contexts. (By external I mean a whole-S context where gerunds appear.) Of course, I do not mean to claim that it is logically impossible to attribute this change exclusively to the inherent factors of gerundive constructions. But the assumption of such an Autonomous development does not seem to agree with the traditional account that the verbal properties of gerunds were BORROwED from such verbals as present participles or infinitives (cf. Mustanoja 1960: 566-73). In general, we cannot gain a correct understanding of the changes that a certain structure underwent under the influence of other related constructions, unless we take into account its external as well as internal contexts. (For a general discussion of this type of linguistic changes, see Section 5.2. and fn. 2) In the case of gerunds, the tangible change is apparently confined to the inside of NP structure containing -ING forms, but we must not overlook intangible contextual effects, if any, that might be relevant to the change in question. ${ }^{2}$

A second serious flaw in the previous studies is their lack of semantic considerations. The traditional account for the development of verbal

${ }^{1}$ For a different analysis of this change, see Niwa 1987. She discusses the implications of the recent GB-theory for the development of verbal gerunds.

${ }^{2}$ This is one of the most important methodological points that diachronic linguists always have to keep in mind. If syntactic forms of particular categories (such as S, NP, VP, AP, etc) undergo any changes, we must not exclude, in advance, any possibility that their EXTERNAL contexts, outside the particular categories, might be a crucial condition for the changes. To make clear this point, let us take a typical example. It is generally believed that the word order change from SOV to SVO occurred predominantly in main clauses at the earlier period, and later extended to subordinate clauses (cf. Lightfoot 1979: 125-8). Speaking from the viewpoint of generative grammar, this change took place within the same category $\mathrm{S}$, since both subordinate and main clauses are members of the $S$. But taking into account wider surroundings outside the $S$, we can technically distinguish and capture the notion of EMBEDDED-S and ROOT-S. Only by so doing, can we consider such interesting diachronic topics as LOCUS OF SYNTACTIC CHANGES Or EXTENTION OF SYNTACTIC CHANGE. 
gerunds is that the suffix of the present participle, -inde, was morphologically and phonologically merged into that of the verbal substantive, -ing, with the result that the former gave the latter syntactic properties (i.e., verbal properties). ${ }^{3}$ In this case, however, the traditional account has not touched upon any semantic relation between these two nonfinite forms. We have to admit here that this kind of account is the less persuasive for lack of semantic reasoning. It seems rather natural to think that when two syntactic forms influence each other, bringing about a novel structure, some semantic aspects of them could be crucially involved in this process. Needless to say, semantic aspects of syntactic constructions of the earlier stage are especially difficult to approach. But we could say here that if we can find any clue to the semantics of the gerund and the present participle, it will prove to be a great step toward the verification of the traditional account given above.

In the present paper, I will tackle these two problems by introducing a new angle of observation into this diachronic phenomenon. ${ }^{4}$

2. Aims and Data. In this section, keeping in mind the two problems raised in Section 1, I will present two aims of this study, and touch briefly upon the corpus on which the present study is based.

2.1. External Structure. The original -ING form acquired several verbal properties in the process of its development:

(1) a. cooccurrence with adverbials

b. taking the object without the intervention of of

c. cooccurrence with passive or perfect morphemes

In what follows, I will concentrate on the second verbval property, $1 \mathrm{~b}$, and investigate those external contexts in which this property began to emerge in Late ME (henceforth, LME); to put it another way, I will explore the initial locus of the change from Type A or B to Type C or D:

(2) Type A: the refusing of the offer

Type B: refusing of the offer $\}$-Nominal Gerund

${ }^{3}$ Infinitives, along with present participles, are supposed to have been partly responsible for this change. Cf. Mustanoja 1960: 572.

${ }^{4}$ Emonds 1973 also fails to get over these two problems, although his consideration as to the effects of present participles on gerunds is stimulative and suggestive. Incidentally, it seems to me that his failure stems partly from the selection of data from Chaucerian English. For the problem of selecting data, see Section 2.1. 
$\left.\begin{array}{l}\text { Type C: the refusing the offer } \\ \text { Type D: (John's) refusing the offer }\end{array}\right\}$-Verbal Gerund ${ }^{5}$ As is well known, LME is the period in which Types A and B were prevalent, and in which the less prevalent Types $C$ and $D$ began to show initial signs of growth. What is most interesting to us is to see whether the development from $\mathrm{A}$ and $\mathrm{B}$ to $\mathrm{C}$ and $\mathrm{D}$ was dependent on some aspects of the external environments of the construction. The first aim of this paper is to clarify this point.

Now let us refer briefly to the text to be examined in the present study. Among extensive corpus available, I have chosen Paston Letters of the fifteenth century (henceforth, PL). PL has many linguistic advantages: homogeneity of materials, extensiveness of data, prose data, informal, educated style, etc. The selection of this text is also important from the chronological point of view. Thus, the period later than the fifteenth century is too late for us to identify the beginning stage of Types $\mathrm{C}$ and D, since in Early ModE these constructions were already extended into broader environments. In contrast, the period earlier than the fifteenth century seems too early for us to collect sufficient number of examples. Thus, both too MANY and Too FEw examples prevent us from properly recognizing the critical stages of the development of verbal gerunds.

To sum up, our first goal is to answer the following question. In what external contexts did the change from nominal to verbal gerund (i.e., from Type A or B to C or D) begin to appear in the earlier stage? Suppose now that the answer to this question is Ex (a particular external context).

2.2. Semantics of Two Verbals. After designating Ex, we will have to consider the connection between the semantics of present participles and that of gerunds used in Ex. If there is such a connection, it will lend semantic support to the conventional hypothesis that syntactic properties transmitted from present participles to gerunds, as a result of phono-

5 The term 'Verbal Gerund' usually refers to Type D alone. But in this paper we shall use it to refer to both Types $C$ (the so-called MIXED GERUND, a marginal construction) and D. Although a definite article in the former apparently exhibits a nominal character of the construction involved, it is not our primary concern. As was said earlier, in what follows, attention will be focused upon the verbal property of taking the object without of. I believe nothing crucial hinges on this decision. 
logical and morphological merger of the suffixes of the two verbals that were originally distinct from each other. Thus, the second aim of this paper is to see if we could relate the semantic function of present participles to that of gerunds in Ex.

3. Numerical Distribution of Verbal Gerunds in PL

3.1. Biased Distribution. To begin with, let us show some of the typical environments where the Verbal Gerunds in Present-day English can appear:

(3) a. Subject: Watching television keeps them out of mischief.

b. Direct Object: He enjoys playing practical jokes.

c. Subject Complement: Her first job had been selling computers.

d. Adjectival Complementation: They are busy preparing $a$ barbecue.

e. Prepositional Complement: I'm responsible for drawing up the budget.

(Quirk et al. 1985: 1063)

We shall next give the numerical distribution of Types C and D in PL corresponding to each of the five functions, 3a-e.

Table I

$\begin{array}{lllllr} & 3 a & 3 b & 3 c & 3 d & 3 e \\ \text { Type C } & 0 & 0 & 0 & 0 & 3 \\ \text { Type D } & 0 & 0 & 0 & 0 & 43\end{array}$

Interestingly enough, Table I shows that the occurrences of $\mathrm{C}$ and $\mathrm{D}$ were limited exclusively to $3 \mathrm{e}$, prepositional complements. Here it should be emphasized that it is possible to find many instances of Types A and B in broader contexts, as illustrated below: ${ }^{6}$

(4) a. Subject: my lord may verily knowe that the complysshyng of pe seid appoyntement is nat deferred ner delayed by me. (547.12-4)

b. Direct Object: ye may justyfye the kepyng of the plase for the pesybyll possessyon that ye haue had in it mor then iij yeer. (342.20-2)

c. Subject Complement: the hasty purchace of mony and

${ }^{6}$ All the citations given below are from Norman Davis' edition. References are made to letter numbers and lines in that order. 
men schall be the getyng and rescu of it (243.47-8)

d. Adjectival Complementation: no instance ${ }^{7}$

e. Prepositional Complement: wherof the date is the day of makyng of thiez presentz, (253.7-8)

Especially noticeable is the fact that we can find instances of Types A and $\mathrm{B}$ not only in $3 \mathrm{e}$ but also in 3a-c. One might think that the attested gap in 3a-d of Table I can be partly due to the general tendency of Types A and $B$ to occur more frequently in $3 e$ than in $3 a-d$. Although some allowance must be made for this possibility, it remains to be seen why the occurrence of Types $\mathrm{C}$ and $\mathrm{D}$ shows such a distinct distributional bias toward a particular context, while A and B can emerge in wider contexts.

3.2. Prepositional Complements. Next let us examine those 46 instances in more detail. According to Quirk et al. 1985: 657, prepositional phrases have the following three functions:

(5) a. Complementation

(i ) of V: look at

(ii) of A: afraid of

b. Post-modifier in NP

c. Adverbials

Table II below shows the numerical distribution of Types C and D in PL corresponding to each of the three functions:

\section{Table II}

$\begin{array}{lllr} & 5 \mathrm{a} & 5 \mathrm{~b} & 5 \mathrm{c} \\ \text { Type C } & 0 & 1 & 2 \\ \text { Type D } & 1 & 6 & 36\end{array}$

Let us give individual examples.

The following is the only example of 5a-i, complementation, where a prepositional phrase is closely related to a preceding verb, ceace.

(6) we ... commanded yow ... to have ceased of makeinge any assemblye of our people (757.2-5)

${ }^{7}$ Notice here that there is no instance of Types A and B in the context of Adjectival Complement. It is not surprising in the light of the fact that even in Present-day English such instances are severely restricted to a few adjectives, such as busy, near, and worth. 
There are 7 instances of $5 b$, post-modifier-in-NP. In these cases, it is uncertain whether there is any particular restriction on the nouns followed by this PP.

(7) a. as for the justificacyon of entryng the place and sege layng to the same, (242.88-9)

b. to fynde the meanes how I myght beste be spedde for the licence of morteisyng certein lyuelode, (569.34-6)

c. I had no comffortable answere of spedyng the seid paymentes here, (604.22-3)

d. all was oon thyng in substance of puttyng you in knolege of the Kyng your vncles deth, (646A.5-6)

e. if he graunt my brodyr Edmund Clyppysbys son in recompence for takyng my brodyr Edmundys son, (381.55-7)

$*_{\mathrm{f}}{ }^{8}$ for grete remorse I haue in my soule of the vntrewe forgyng and contryvyng certayne testamentys and last wyll by naked wordes ... (901.31-3)

g. my maistyr was right well pleasyd wyth youre feithefull labour in fulfellyng the patent for the warrd of A.B.C, (510.3-4)

Finally, our investigation reveals the highest freqency of $5 \mathrm{c}$, adverbial PP. Eight (compound) prepositions are involved in 38 instances of this construction: after, as for, because of, for, in, of, on, and without. A complete list of the examples is given below.

(8) (i ) AFTER (one instance):

*a. with-in vj dayes aftire the so takyng aswell the names of the sayd prisoners as theire estate degre, or condicioun (396.54-5)

(ii) AS FOR (3 instances):

a. as for callyng vppon the replevyn that the bestys of Drayton were delyueryd by. (183.36-7)

b. as for ... yevyng the maner of Castre or hys londes in Norffolk to John Paston ... (895A.12-3)

$*_{c}$. as for the letyng me haue knowlage of the areragys of your lyuelod, (336.32)

(iii) BECAUSE OF (one instance):

a. because of castyng Bradwell and Tychewell yn the Kynges handes, (566.26-7)

${ }^{8}$ An asterisk preceding an example indicates Type C. 
(iv) FOR (5 instances):

a. but as a drane amonges bees whech labour for gaderyng hony in the feldes (72.38-9)

b. ye were not troubled ne vexid for lettyng the execucion of my seyd lordes wille (538.7-8)

c. I haue aforetyme ben accused vnto the Kinges highnesse and the Quenes for owyng my pouere gode will and seruice vnto my lord of York and oper, \&c. (575.11-3)

d. Other examples: (626.9-10) (626.1-2)

(v) IN (25 instances):

a. I neuir coud fele ner vndirstand hym poletyk ner diligent in helpyng hym-self, (72.37-8)

b. Be ware how that ye spend it but in acquityng you ageyn such as ye be in daungere to, (208.11-2)

c. Robert Lethum and his men assauted on John Coke of Witton, in brekyng vppe his dorys atte a xj of the cloke in the nyght; (48.80-2)

d. I founde Herry Greye, Lomnour, ... ryght weele disposed to you ward at this tyme in helpyng and in gevyng ther goode avice to me for suche maters as I had to doo. (189.85-8)

e. my nevew, whome I hartely beseche in executyng and performyng this my laste will to do and dispose ... (113.935)

f. thynkyng you allys mete a man in executyng there comaundement as cowde be chosyn (242.44-5)

g. I haue no worde from you of them, ner whethere ye haue yit in yowr kepyng the euydence of Est Bekham owt of hys handys, (243.65-6)

h. Butt the Kyng ententyth in eschyewyng all jnconvenyentys to be as bygge as they bothe, (281.5-6)

i. I beseke yow to be my good maystyr in pursewyng the seyd ateynte. (511.4-5)

j. he myst do grete ease, as yn disavowyng of it or yn wythdrawyng it owte of the bok. (559.4-5)

k. Other examples: (92.22-3) (310.1-2) (572.24-5) (634.8-9)

$$
\begin{array}{llr}
(686.14-7) & (686.65-9) & (700.5-8) \\
(811 \mathrm{~A} .1-4) & (864.14-6) & (881.48-50) \\
(893.9-10) & (894.16-8) & (901 \mathrm{~B} .5-7)
\end{array}
$$


(901B.17-9) (912.48-50)

(vi ) OF (one instance):

a. James Cook ... hath accused and diffamed me and my wif of settyng vp billes agayn lordis (492.8-10)

(vii) $\mathrm{ON}$ (one instance):

a. Ye nede at this tyme rather to have had three solicitours than in ony other terme past this iij yere, on concyderyng the maters hangyng, \&c. (601.14-6)

(viii) WITHOUT (one instance):

a. they treuly pay or agré for, and frendly entrete our seyd cousyns subiectys withowth eny robbyng or exstartyng them in there bodyes ner goodys, (824.14-6)

So far we have given all the individual examples of Types C and D in PL, and classified them from the functional point of view. The total picture of their numerical distribution is summarized in Table III below:

Table III

\begin{tabular}{|c|c|c|c|c|c|}
\hline Subject & & & & 0 & \multirow{14}{*}{$43,3 *$} \\
\hline Direct Object & & & & 0 & \\
\hline $\begin{array}{l}\text { Subject } \\
\text { Complement }\end{array}$ & & & & 0 & \\
\hline $\begin{array}{l}\text { Adjective } \\
\text { Complement }\end{array}$ & & & & 0 & \\
\hline \multirow{10}{*}{$\begin{array}{l}\text { Prepositional } \\
\text { Complement }\end{array}$} & Complementation & & & 1 & \\
\hline & Postmodifier in NP & & & $6,1^{*}$ & \\
\hline & \multirow{8}{*}{ Adverbial } & \multirow{8}{*}{ Adjunct } & after & \multirow{8}{*}{$36,2^{*}$} & \\
\hline & & & as for $2,1^{*}$ & & \\
\hline & & & because of 1 & & \\
\hline & & & for & & \\
\hline & & & in $\quad 25$ & & \\
\hline & & & of & & \\
\hline & & & on & & \\
\hline & & & without & & \\
\hline
\end{tabular}

4. Discussions

4.1. Context-Sensitive Development. The result of our detailed investigation of PL reveals many interesting phases of the development of 
verbal gerunds that previous studies have failed to observe. As can be readily seen from Table III, the distribution of Types $C$ and $D$ are severely restricted. Especially important is the scarcity of occurrence in contexts other than prepositional complements. Moreover, the majority of the cases of prepositional complements exhibit an interesting distribution. Thus, they occur more frequently in Adverbial PP than in Post-modifierin-NP or Complementation. These facts seem to imply, among other things, that the initial stage of the development of verbal gerunds (i.e., Types $C$ and D) was more or less sensitive to some factors relating to their external environments. If Types $\mathrm{A}$ and $\mathrm{B}$ had acquired verbal properties irrespective of their external contexts, then Types $C$ and $D$ could have occurred in all the positions in which nouns could usually appear (cf. Emonds 1971: 194). However, so long as we look into PL, the change in question seems to have taken place only in the limited contexts. That is one argument for regarding this change as CONTEXT-SEnsitive.

This CONTEXT-SENSitive hypothesis leads us to conjecture that the final (i.e., present-day) stage of this development illustrated in 3, was not reached ABRUPTLY. I am inclined to think that this development progressed gradually from the initial stage attested in this study toward the present-day stage. Exact nature and chronology of this process are yet to be seen, but we could safely say for the moment that verbal gerunds, as evidenced in this study, entered primarily into the context of $3 \mathrm{e}$ (prepositional complement) in ME, and later in EModE extended to other contexts such as $3 a-d .{ }^{9}$

4.2. Preposition in and Its Special Status. Another interesting implication that our investigation has for the mechanism of the change under consideration is deeply connected with the special status of the preposition in. As is evident from Table III, among various prepositional usages, the adverbial use of in shows the strikingly high frequency of cooccurrence with Types C and D. This fact suggests that this in-phrase is the initial locus of the development of verbal gerund. In what follows, I will argue that this fact is not simply accidental, and that the preposition in is, so to speak, a KEY to the development of verbal gerunds.

${ }^{9}$ For the description of this development in EModE, see Inazumi 1973-5. His study, based on detailed investigation of Roger Ascham's works, also presents numerical distributions of various kinds of ING forms, the results of which seem to be by and large consistent with this conclusion. 
Let us recall the question posed in Section 2.1. In what external contexts did the change from nominal to verbal gerunds begin to appear at the earlier stage? Now we are in a position to answer this question. A most likely candidate for this answer, Ex (cf. Section 2.1.), is an adverbial phrase introduced by in.

Keeping in mind this prospective answer, let us turn to the second question raised in Section 2.2. The question was whether there is any overlap or similarity between the sematic function of present participles in LME, on the one hand, and that of the verbal gerunds of Types $\mathrm{C}$ and $\mathrm{D}$ appearing in the context Ex, on the other. If there is such semantic similarity, it will give additional support to the conventional argument mentioned in Section 1.

To answer the above question, let us begin with reviewing the usages of present participles in ME. We could name several types of constructions with present participles:

(9) (i ) participial constructions

(ii) progreesive constructions

(iii) participles following the so-called PERCEPTION VERBS

(iv) MANNER PARTICIPLES following such verbs as go, come, lie, stand, etc.

Let us direct our special attention to the semantics of 9i, participial constructions in ME. It should be noted that one of their principal meanings was TEMPORAL (cf. Mustanoja 1960: 555-6); ${ }^{10}$ thus, the semantics of participial constructions is considered to be almost equivalent to that of subordinate clauses preceded by when or while. Interestingly enough, the TEMPORAL interpretaion holds true of the verbal gerunds appearing in Ex, that is, of the phrase 'in + V-ing + Object'. As is obvious from the definitions of in in OED and MED, and from the interpretations of the examples adduced in $8 \mathrm{v}$, this prepositional phrase also conveys the TEMPORAL meaning that can be expressed by when, while or 'in the course of (action)'. Therefore we might conclude that such semantic overlap between the participial construction and the in-phrase (exactly speaking, 'in + V-ing + of Object') enabled the latter construction to acquire verbal property of taking the object directly; the semantic factor facilitated the borrowing of a syntactic property from present participles.

${ }^{10}$ Of course, in ME there were other adverbial usages meaning REASON, CONCESSION, CONDITION, Or ATTENDANT CIRCUMSTANCE. 
This conclusion is consistent with the peculiar fact observed in the present study that the novel verbal gerund ( $\mathrm{V}$-ing + Object) appeared in the restricted context of in-phrases. In this way, I have argued that the semantic similarity is a prerequisite for the initial development of verbal gerunds, although other factors might be relevant to their subsequent development. ${ }^{11}$ I hope I have shown that combined with the contextsensitive hypothesis proposed in the preceding section, the above consideration as to in serves to semantically justify the traditional account that present participles partly triggered the development of verbal gerunds. $^{12}$

5. Concluding Remarks: New Angle of Observation. If my argument that some aspects of the development of verbal gerunds were subject to external conditions is on the right track, then it will shed new light upon diachronic treatment of historical facts. In this paper I hope I have shown that one syntactic change that at first glance appears to have occurred within NP structure turns out to be crucially contingent on its external environments. Another change of similar kind is treated in Jones 1967 , which is concerned with the disappearance of grammatical

11 In spite of the variety of prepositions, verbal gerunds in the initial stage of development tend to cooccur with a particular preposition in. Why? Prepositions have different semantic scope; for example, LOCATIONAL or TEMPORAL in has larger semantic scope than another preposition at. A rough survey of the definitions of in in OED, MED, and other dictionaries reveals that the preposition in had relatively wide semantic scope in those days. Besides the temporal meaning, the in contains many other meanings. The wider semantic scope of in might be partly responsible for its highest frequency of coocurrence with verbal gerunds. It is not clear for the moment whether such difference in scope has anything to do with the development in question. To answer the question we will have to collect more data especially concerning other prepositions pertinent to verbal gerunds.

12 One has to discuss the adequacy of the contention that infinitives, in addition to present participles, also played an important role in causing the change under analysis (cf. fn. 3).

Our account based on the semantic similarity between participles and in-phrases cannot explain the cases with prepositions signifying PURPOSE, such as for-phrases (cf. 8iv), since to my knowledge there is no historical evidence to show that participial constructions were used as purpose adverbials. However, infinitives, unlike present participles, are qualified as adverbials of PURPOSE, and at the same time, they, like participles, have VP-like internal structures. Consequently, it is not unlikely that infinitives too took part in the evolution of verbal gerunds. We will have to examine this possibility in more detail. 
gender system. His study suggests that in the transitional period from Late $\mathrm{OE}$ to Early ME, an ending - ne, which had originally been a marker of singular, masculine and accusative, was extended so far as to those NP cases whose head noun was feminine or neuter. The point here is that this extension process occurred not uniformly in all NP's, but under a particular contextual condition; thus, the change took place in the context of $\mathrm{V}_{-}$, but not in $\mathrm{P}_{\text {_ }}$. Apart from the minute differences between our analysis and Jones', the two analyses share the following angle of observation: an innovation that apparently took place within an NP was proved to be constrained by the environments outside the NP. It is a very interesting problem whether those changes which we observed can also be attested in categories other than NP (cf. fn. 2). If they can, their general properties and mechanisms of linguistic change must be elaborated in future studies.

\section{REFERENCES}

Araki, Kazuo, and Masatomo Ukaji. 1984. Eigo-shi (English history) III-A. Tokyo: Taishukan.

Curme, George O. 1912. History of the English gerund. Englische Studien 45. $348-80$.

Emonds, Joseph E. 1973. The derived nominals, gerunds, and participles in Chaucer's English. Issues in linguistics, ed. by Braj B. Kachru, Robert B. Lees, Yakov Malkiel, Angelina Pietrangeli, and Sol Saporta, 185-98. Urbana: University of Illinois Press.

INAZUMI, KANEAKI. 1973-5. Roger Ascham no gengo (Roger Ascham's language) I:

Gerund i-iii. Bulletin of Toyama University.

JACKENDOFF, RaY S. 1977. X-bar syntax. Cambridge, MA: MIT Press.

JONES, ChARLES. 1967. The grammatical category of the gender in Early Middle English. English Studies 48.289-305.

Koma, Osamu. 1980. Diachronic syntax of the gerund in English and the X-bar theory. Studies in English Literature (English Number 1980), 59-76. The English Literary Society of Japan.

Lightfoot, David. 1979. Principles of diachronic syntax. Cambridge: Cambridge University Press.

Mustanoja, Tauno F. 1960. A Middle English syntax. Helsinki: Société Néophilologique.

Nakao, Toshio. 1972. Eigo-shi (English history) II. Tokyo: Taishukan.

NaKashima, Kunio. 1981. Studies in the language of Sir Thomas Malory. Tokyo: Nan'undo.

Niwa, MakiYo. 1986. Gerund no hattatsu to kaku-sosei no kanren ni tsuite (On the advent of syntactic affix -ing: Some remarks on gerundive constructions). 
Studies in Modern English 3.53-70. Modern English Association.

Ono, Shigeru, and Toshio Nakao. 1980. Eigo-shi (English history) I. Tokyo: Taishukan.

Quirk, Randolph, Sidney Greenbaum, Geoffrey Leech, and Jan Svartvik. 1985. A comprehensive grammar of the English language. London: Longman.

Saito, Toshio. 1971. The construction of the gerund with its object in Early Modern English. College of General Education, University of Osaka, 171-86. Tajima, Matsuji. 1977. 14seiki ni okeru domeishi-sono doshiteki seisitsu no hattatsu ni tsuite (The gerund in the 14th century English with reference to the development of its verbal character). Eibungaku kenkyu (Studies in English Literature) 54.113-33. The English Literary Society of Japan. 1985. The syntactic development of the gerund in Middle English. Tokyo: Nan'undo.

Visser, Frederikus Theodorus. 1966. An historical syntax of the English language. II. Leiden: E. J. Brill. 